\title{
ANATOMICAL VARIATION OF INTRAHEPATIC BILIARY DUCT IN CADAVERIC LIVER
}

Sushma Khatiwada ${ }^{1, *}$, Budhi Nath Adhikari ${ }^{2}$, lju Shrestha ${ }^{3}$

${ }^{1}$ Department of Anatomy, Chitwan Medical College, Bharatpur 10, Nepal

${ }^{2}$ Department of Surgery, Chitwan Medical College, Bharatpur 10, Nepal

${ }^{3}$ Department of Anatomy, Kathmandu Medical College, Kathmandu, Nepal

Received: 10 Nov, 2019
Accepted: 11 Dec, 2019
Published: 27 Dec, 2019
Key words: Blumgard's classification; Cadaveric liver;
Intrahepatic biliary ducts.

*Correspondence to: Sushma Khatiwada, Department of Anatomy, Chitwan Medical College, Bharatpur, Chitwan, Nepal.

Email: khatiwadasushz@gmail.com

DOI:https://doi.org/10.3126/jcmc.v9i4.26892

Citation

Khatiwada S, Adhikari BN, Shrestha I. Anatomical variation of intrahepatic biliary duct in cadaveric liver.2019;9(30):11-14.

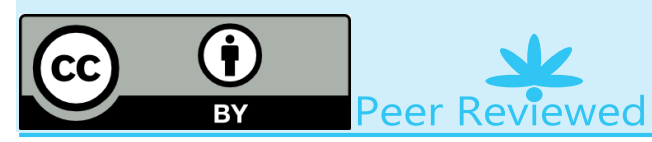

INTRODUCTION

Having a sound anatomical knowledge of the biliary tract is important while performing surgical interventions around the hilum. Incorrect interpretation of the anatomy during laparoscopic cholecystectomy, the commonest intra-abdominal operation, heralds potentially avoidable grave consequences to the patient. Advances in surgical procedures for liver resections and partial liver transplantation have demanded a better and more detailed understanding of biliary anatomy and their potential variations. ${ }^{1}$

The right hepatic duct and its branches are subject to more variations than the left ductal system, and these variations have been classified by Blumgart into six main types (Table 1). ${ }^{2}$ Wide variations of typical bile duct pattern have been documented in the literature from across the globe. ${ }^{2-5}$ It has been an unexplored field of research in Nepal as only a single study of right hepatic duct at Patan Academy of Health Sciences has been reported till date. ${ }^{6}$

This study aimed to explore the anatomy of the intrahepatic biliary ducts and their variations in the context of Nepalese population.
Table 1. Blumgart's classification of Hepatic Duct confluence

\begin{tabular}{|l|l|}
\hline Type & Description \\
\hline A & Anatomy is normal. \\
\hline B & $\begin{array}{l}\text { There is no right hepatic duct and the common he- } \\
\text { patic duct is formed by the right anterior, right pos- } \\
\text { terior and left hepatic ducts as a trifurcation. }\end{array}$ \\
\hline C & $\begin{array}{l}\text { There is a low drainage of one the right sectoral } \\
\text { ducts into the common hepatic duct. }\end{array}$ \\
\hline D & $\begin{array}{l}\text { One of the right sectoral ducts joins the left hepatic } \\
\text { duct. }\end{array}$ \\
\hline E & $\begin{array}{l}\text { The common hepatic duct is formed by the union of } \\
\text { two or more ducts from either lobe. }\end{array}$ \\
\hline F & $\begin{array}{l}\text { The right posterior sectoral duct drains into the } \\
\text { cystic duct. }\end{array}$ \\
\hline
\end{tabular}

\section{METHODS}

An observational study was carried out in the Department of Anatomy at Kathmandu Medical College and Teaching Hospital from July 2013 to June 2014 by taking 50 complete cadaveric livers as samples. Stored livers from previously dissected cadavers were used. Previously operated and injured livers were excluded from this study. The method used for preparation and 
evaluation is illustrated in Figure 1. For the collection of data, structured proforma was used.

\section{Preparation and Evaluation of sample}

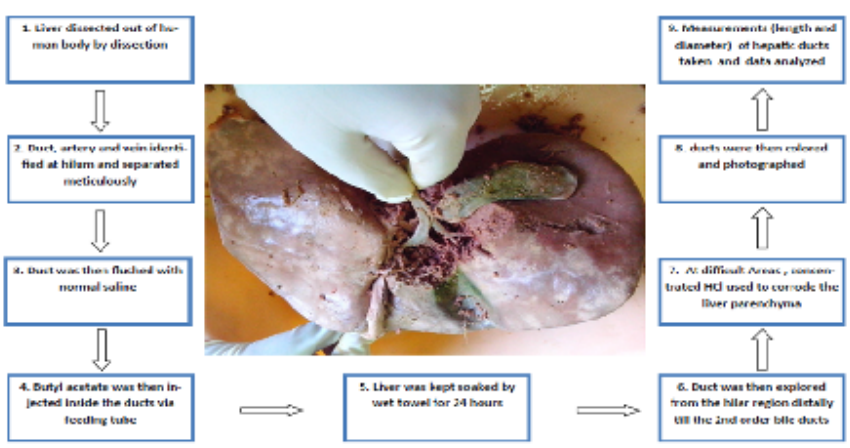

Figure 1 : Preparation of the liver for the study

Study approval was obtained from The Ethics \& Research Committee of Kathmandu Medical College and Teaching Hospital. Permission from the Department of Anatomy was also taken for the collection of data. Statistical analysis was performed by using the program SPSS Version 16. Percentage was computed for frequency of confluence of right and left hepatic duct. Charts were used whenever necessary.

\section{RESULTS}

A total of 50 livers were dissected during a period of 12 months at the Department of Anatomy, Kathmandu Medical College and Teaching Hospital, Duwakot. The right and left hepatic ducts were dissected till the formation of common hepatic duct. In each case right lobe of liver was drained by two main ducts, the posterior segmental duct and anterior segmental duct. The left lobe was drained by two main ducts: lateral segmental duct and medial segmental duct.

Out of $50(n=50), 32$ dissected livers showed typical pattern of confluence (64\%) and 18 liver showed atypical pattern of confluence (36\%). The distribution of the atypical pattern of the bile ducts are shown as bar charts in Figure 2.

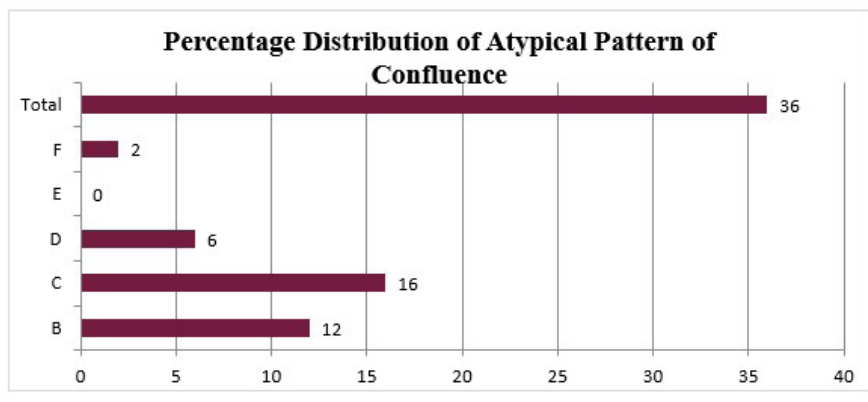

Figure 2: Percentage of atypical pattern of confluence

The type B observed in the study was seen in 6 livers. Type $C$ was seen in 8 cases. Of these 8 cases, 6 were of the subtype $C 1$ and 2 were of the subtype C2. Type D was seen in 3 livers and all were of the subtype D1. There were no cases of subtype D2 and type E pattern was not seen. Type F was observed in a single case. An example of type A is shown in Figure 3.

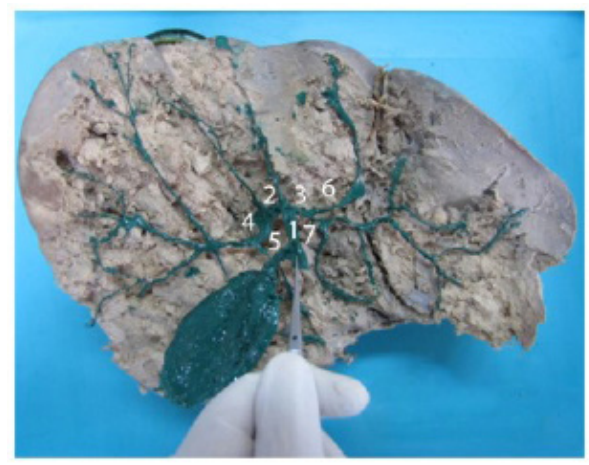

1 - Common Hepatic Duct

2 - Right Hepatic Duct 3 - Left Hepatic Duct

4 - Anterior Segmental Duct

5 - Posterior Segmental Duct

6 - Medial Segmental Duct

7 - Lateral Segmental

Duct

Figure 3: Typical (Type A) pattern of bilary confluence-CHD formed by union of RHD and LHD

\section{DISCUSSION}

Anatomical variability is a rule rather than an exception in the biliary system. ${ }^{3}$ Kostov et al ${ }^{4}$ had pointed out that the actual number of biliary tract anatomic variations was difficult to estimate due to differences in the study populations and methodologies used.

Typical biliary pattern of the confluence was found in $64 \%$ in the present study which was comparable to the 60 - $65 \%$ range given in Yamada Textbook of Gastroenterology. ${ }^{7}$ However, other studies ${ }^{2,8-10}$ have showed a wide range of normal pattern from as low as $36 \%$ to as high as $75.8 \%$. Four studies from the south east Asia, including one from Nepal, ${ }^{6}$ had found typical pattern in $53-77.65 \%$ cases $^{8,11,12}$ which seems to be higher as compared to other geographical locations. ${ }^{8,10.13-16}$ This may be related to racial or some environmental differences which needs to be clarified with further studies.

Triple confluence (type B) was present in $12 \%$ of our cases $(n=6)$ and between $5 \%$ and $16 \%$ of patients in other studies. ${ }^{3,4,8,13}$ Similar findings were also documented by Couinaud et al $(12 \%)^{2}$ and Ozsoy et al (12.3\%). ${ }^{16}$ In patients with this variant, the right hepatic duct is virtually nonexistent. This variation causes an increased risk of damage to the bile drainage of the right segments during a left hepatectomy. ${ }^{4}$

Type $\mathrm{C} 1$, in which the right anterior segmental duct drains into the common hepatic duct, was found in $12 \%(n=6)$ in the present study. This is almost identical to other similarly reported rates. ${ }^{6,17}$

Bile draining from the right posterior sector into the Common Hepatic Duct (type C2) was seen in $4 \%(n=2)$ of our cases whereras it was found in $4.5-16 \%$ in previous studies. ${ }^{3,4,5,15}$ In patients with type $\mathrm{C} 2$ anatomy, who undergo laparoscopic cholecystectomy, the right posterior segmental branch might be mistaken as cystic duct and erroneously divided. ${ }^{18}$

The right posterior sector draining into the Left Hepatic Duct (LHD, type D1) was found in $6 \%$ of our cases $(n=3)$. This is the most commonly reported variation of atypical pattern of intra- 
hepatic biliary radicles in the literature with rates from $13-$ $19 \%{ }^{2,3,8,13}$ but Theodoros et al ${ }^{18}$ had reported it in only $4.11 \%$ of his cases which is similar to the present result. This alteration may result in biliary stasis and relapsing cholangitis during a left hepatectomy as a result of interruption of biliary drainage. ${ }^{4}$ Identification of this anatomic variation is important while performing endoscopic or percutaneous biliary drainage procedures as well. Since it can result in drainage of the left side of the liver and posterior segment of right side, left-sided percutaneous transhepatic biliary drainage (PTBD) or endoscopic biliary drainage (EBD) of the LHD is preferable in patients with hilar blocks, periportal metastatic disease, or gallbladder carcinoma where there is a risk of multiple segmental ductal obstructions. In certain biliary disease, such as hepatolithiasis, it is theorized that the ramification pattern of Intra Hepatic Duct may affect hepatic bile flow, leading to biliary stasis and subsequent secondary bacterial infection and recurrent pyogenic cholangitis. The fact that hepatolithiasis is more prevalent in the left lobe may well support this hypothesis. ${ }^{18}$ The LHD joins the Common Hepatic Duct (CHD) at a more acute angle than the Right Hepatic Duct (RHD), and because the most acute angle is created between the Right Posterior Segmental Duct and the LHD in this type, such a patient is, in theory, likely to experience more biliary stasis and a greater incidence of hepatic stone than those with other types. ${ }^{8}$

In this study, subtype D2 was not found in any liver, whereas upto $5.2 \%$ of cases in previous studies reported this subtype. . $, 4,8,14$ The presence of this alteration may increase the risk of cessation of the bile drainage for the anterior segments during a left hepatectomy and bisegmentectomy. The risk of interruption of the bile drainage from the posterior sector during $\mathrm{CHD}$ resection or after a cholecystectomy in patients with this alteration may be increased. ${ }^{4}$

There was a single case of type $\mathrm{F}(2 \%)$ in the present study in

\section{REFERENCES:}

1. Akamatsu et al. Left hepatic trisectionectomy for hilar cholangiocarcinoma presenting with an aberrant biliary duct of segment 5 : a case report. Journal of Medical Case Reports 2010, 4:250. [DOI]

2. Gall Bladder and Biliary Tree. In: Standring S, editor. Gray's Anatomy: The anatomic basis of clinical practice. 40th ed. Churchill Livingstone; 2008.

3. Marcos A, Ham JM, Fisher RA, Olzinski AT, Posner MP. Surgical Management of Anatomical Variations of the Right Lobe in Living Donor Liver Transplantation. Ann Surg. 2000;231(6):824-31. [DOI]

4. Kostov DV, Kobakov GL. Six Rare Biliary Tract Anatomic Variations: Implications for Liver Surgery. The Eurasian Journal of Medicine. 2011;43:6772. [DOI]

5. Chaib E, Ribeiro MAF, Saad WA, Gama-Rodrigues J. The Main Hepatic Anatomic Variations for the Purpose of Split-Liver Transplantation. Transplant Proc. 2005;37:1063-6. [DOI]

6. Kafle A, Adhikari B, Shrestha R, Ranjit N. Anatomic Variations of the Right Hepatic Duct: Results and Surgical Implications From a Cadaveric Study. J Nepal Health Res Counc 2019 Jan-Mar;17(42):90-3. [DOI]

7. Welling $T H$, Simeone DM. Gallbladder and biliary tract: anatomy and structural anomalies. In: Yamada T. Textbook of Gastroenterology. 5th ed. Wiley-Blackwell Publication; 2009. which the right posterior sectoral duct drained into the cystic duct. This type, also called as the cysticohepatic ducts, was reported in $0-6 \%$ of cases., ${ }^{9,14,16}$ It is crucial that in laparoscopic cholecystectomy, this variation is recognized: ligation or resection of an aberrant duct will lead to complications, such as biloma, biliary cirrhosis or bile leakage. ${ }^{17}$ When cholecystectomy is performed in patients with this variation, the cystic duct must be ligated between the gallbladder and the point at which the duct joins the anomalous RHD. ${ }^{8}$

In the present study, type E variation, in which the right and the left main hepatic ducts are not formed, was not found which is unlike that in the other similar studies. ${ }^{2,16,17}$ The use of the various investigative modalities to visualize the biliary tract, a different study population, unknown gender distribution of the samples, friable tissues, different classification schemes of atypical pattern and different sample sizes in the previous studies would make comparisons difficult to reach a single conclusion.

\section{CONCLUSION}

Of the various techniques available to study the anatomy of the intrahepatic biliary ducts, cadaveric dissection method was used and the distubution pattern in Nepalese population was documented. We found a different distribution of the atypical pattern of confluence, so larger population-based studies are needed to find the true prevalence of the pattern in our population.

\section{CONFLICT OF INTEREST}

\section{None}

\section{FINANCIAL DISCLOSURE}

\section{None}

8. Sharma V, Saraswat VA, Baija SS, Choudhuri G. Anatomic variations in intrahepatic bile ducts in a North Indian population. J Gastroenterol Hepatol. 2008;23(7):e58-e62. [DOI]

9. Kim HJ, Kim MH, Lee SK, Seo DW, Kim YT, Lee DK et al. Normal structure, variations, and anomalies of the pancreaticobiliary ducts of Koreans: a nationwide cooperative prospective study. Gastrointest Endosc. 2002;55:889-96. [DOI]

10. Varotti G, Gondolesi GE, Goldman J et al. Anatomic variations in right liver living donors. J Am Coll Surg. 2004;198(4):577-82. [DOI]

11. Deka P, Islam M, Jindal D, Kumar N, Arora A, Negi SS et al. An analysis of biliary anatomy according to different classification systems. Indian Gastroenterol. 2014 Jan-Feb;33(1):23-30. [DOI]

12. Gupta CD, Mittal VK, Gupta SC. Intrahepatic Pattern of the Biliary Ducts and their Major Variations. Indian J Med Res. 1975;63(8):1130-7. [PMID]

13. Choi JW, Kim TK, Kim KW et al. Anatomic Variation in Intrahepatic Bile Ducts: an Analysis of Intraoperative Cholangiograms in 300 Consecutive Donors for Living Donor Liver Transplantation. Korean J Radiol. 2003;4:85-90. [DOI]

14. Huang TL, Cheng YF, Chen CL, Chen TY, Lee TY. Variants of the bile ducts: clinical application in the potential donor of living-related hepatic transplantation. Transplant Proc. 1996;28:1669-70. [PMID]

15. Ohkubo M, Nagino M, Kamiya J, Yuasa N, Oda K, Arai T et al. Surgical 
anatomy of the bile ducts at the hepatic hilum as applied to living donor liver transplantation. Ann Surg. 2004;239:82-6. [DOI]

16. Ozsoy M, Zeytunlu M, Kilic M, Alper M, Sozbilen M. The Results of Vascular and Biliary Variations in Turks Liver Donors: Comparison with Others. ISRN Surgery. 2011;1-9. [DOI]

17. Mortele KJ, Ros PR. Anatomic variants of the biliary tree: MR cholangio- graphic findings and clinical applications. Am J Roentgenol. 2001;177:389 94. [DOI]

18. Mariolis-Sapsakos T, Kalles V, Papatheodorou K, et al. Anatomic variations of the right hepatic duct: results and surgical implications from a cadaveric study. Anat Res Int 2012;838179. [DOI] 